\title{
An Assessment of Environmental Consciousness Level of University Students of Hisar City
}

\author{
Vinod Joon * and Krishan Kumar** \\ *Department of Community Health Administration, National Institute of Health \& Family \\ Welfare, Munirka New Delhi 110 067, India \\ Telephone: 011-26107773,9868704901.E-mail: ratheev_77@yahoo.co.in \\ ** Faculty SES, Jawahar Lal Nehru University, New Delhi, India
}

KEYWORDS Consciousness Level. Environmental Issues. Media

\begin{abstract}
The present study was conducted on the university students of Hisar city. 65\% students of postgraduate (PG) and 35\% students of undergraduate (UG) level were interviewed. Scoring was done for each subject, then a scale was devised and the scores were accordingly classified in good, moderate and poor category. Results revealed that the average score of consciousness level for PG as well as UG student was same i.e., of moderate category. Regarding use of polythene maximum students $(68 \%)$ show lack of consciousness in spite of their high education level. The same was true for avoiding mosquitoes as $80 \%$ students preferred repellent mats, spray or odomos. About the quality of drinking water $75 \%$ students were conscious. On the question of use of unleaded vs. leaded petrol and inverter vs. generator, the consciousness levels were quite high. Similarly $78 \%$ students appreciated natural beauty and preferred to visit National park/sanctuary or a hill station for recreational purpose. Television and newspaper were the main sources of information for students though interpersonal communication was also important medium to keep people aware regarding environmental issues and to update their knowledge.
\end{abstract}

\section{INTRODUCTION}

Environment all over the world is being degraded as a result of unplanned industrialization, urbanization, population pressure and human greed, leading to indiscriminate and environmentally incompatible development, over utilization of resources and use of inappropriate technology unmindful of the harm being done to environment. Pollution of any kind is a result of injudicious use of resources and it is a problem of obvious importance that affects human, plant and animal health. Pollution from a wide variety of emissions, as from automobiles and industrial activities has reached critical levels, causing respiratory, ocular and other health problems (WHO, 2004).

Community awareness is the key to community participation. Well- informed and well aware people have more role clarity in environment management. An alert community will take active part in any environmental project and can provide inputs in terms of local knowledge and resources. This will enhance self -reliance and confidence in them. People's participation is important for the success of any project. It is therefore necessary that the community not only realizes the environmental problem but also participate in the eco-system conservation process which involves promoting full understanding of the issues and solutions, soliciting the opinions and preferences of citizens regarding resource use and alternate development strategies. People, however have a tendency to support or participate in any conservation activity only when they are convinced that the programme would benefit them (Mills 1978). It is therefore important that public, at large be informed about the relationship between ecology and economics and also about the importance of sustainable development. Environmental education has been recognised to possess the capabilities to meet the challenges by promoting awareness and knowledge on various environmental issues, changing the attitude of people, generating critical thinking and actions and attaining the goal of sustainable development (Sabri 2004). Each individual is needed to be motivated to voluntarily participate in resource conservation and environment improvement activities. Therefore it becomes important to first find out the awareness/consciousness level of people and then accordingly devise appropriate strategies for implementation of an environmental plan. Identifying the type of media that gives more effective information is equally important to know so as to develop suitable IEC package to enhance the awareness level of people of a particular region (Kumari 1998). 


\section{MATERIAL AND METHOD}

The sample of the study consists of a statistically valid sample of 200 university students of Hisar city. Both male and female students of undergraduate and postgraduate classes were selected for the present study. Simple random sampling technique was employed to select the sample. The objective of the study was to assess the consciousness level of students regarding Environmental matters, to compare the consciousness level of post graduate and under graduate students and to find out the source of information of their knowledge.

However it is pertinent here to draw a distinction between environmental awareness and consciousness as people take both the terms as same thing. Environmental awareness can better be considered as merely the level of knowledge regarding environmental issues possessed by an individual, but a person can be called environmentally conscious only if he/she can derive relevant inferences from the knowledge he/she possesses and thus modify his/ her daily life activities in view of the knowledge attained. A survey was conducted in which the questions pertaining to environmental consciousness, age, sex, educational status and source of information of subjects were asked. Two mark were given to the response indicating the presence of environmental consciousness in the subject and zero mark was given to the response indicating the absence of environmental consciousness in the subject. Following this methodology total score of each subject was calculated. A scale was then devised to indicate the consciousness level of the subject. A score less than 6 was rated as poor, $6-10$ as moderate and the score of more than 10 was rated as good level of environmental consciousness.

\section{RESULTS AND DISCUSSION}

As shown in Table 1, regarding the use of polythene vs. cloth/jute bag $68 \%$ students use polythene bags for everyday marketing reflecting their lack of environmental consciousness. The table also reveals that the tendency of using polythene is more among male students. Similarly on the question of methods of avoiding mosquitoes at home, only $19 \%$ students used mosquito net. When we compared the response of girls and boys we found that only $11.9 \%$ girls students used net, rest of them used the other means that were not eco-friendly, the most popular being repellent mats. The huge publicity of these products by manufacturing companies through electronic media may be the reason behind it. (Vitterso 2005) also reported similar findings in his study in which it was found that consumption practice of community changed in favor of a particular product due to its strong publicity through media. In our study television came out as an important medium of information for students, this could be the reason that they preferred repellent mats in spite of its harmful effects on health. Regarding concern about drinking water safety while on journey, 39\% students used to carry their own water bottle and majority of them were girls $(54.7 \%)$. When the students were asked to express their views about bursting of crackers on the eve of Diwali, 50\%

Table 1: Respondents replies regarding environmental consciousness.

\begin{tabular}{|c|c|c|c|}
\hline Parameter & Male & Female & Total \\
\hline \multicolumn{4}{|c|}{ Carrying Goods for Household Marketing } \\
\hline Polythene bag & 77.5 & 54.0 & 68.0 \\
\hline Own jute/cloth $\mathrm{b}$ & 22.5 & 46.0 & 32.0 \\
\hline \multicolumn{4}{|c|}{ Mode of Transport Used for Small Distances } \\
\hline a. Walking & 44.8 & 45.2 & 45.0 \\
\hline b. Cycle & 20.6 & 7.18 & 14.0 \\
\hline c. Scooter & 31.0 & 45.2 & 38.0 \\
\hline d. Car & 3.4 & 2.38 & 3.0 \\
\hline \multicolumn{4}{|c|}{ Method to Avoid Mosquito at Home } \\
\hline a. Mosquito net & 22.4 & 11.9 & 19.0 \\
\hline b. Insecticide spray & 12.0 & 11.9 & 12.0 \\
\hline Repellent mats & 55.0 & 73.8 & 62.0 \\
\hline Repellent creams & 10.3 & 2.38 & 7.0 \\
\hline \multicolumn{4}{|c|}{ Quenching Thirst While on Journey } \\
\hline \multicolumn{4}{|l|}{ a. Carry own } \\
\hline By cold drinks & 34.4 & 33.3 & 35.0 \\
\hline $\begin{array}{l}\text { Drink water at } \\
\text { stoppage }\end{array}$ & 37.9 & 11.9 & 26.0 \\
\hline \multicolumn{4}{|c|}{ Bursting Crackers on the Eve of Diwali } \\
\hline a. Yes & 48.2 & 51.7 & 50.0 \\
\hline b. No & 45.2 & 54.7 & 50.0 \\
\hline \multicolumn{4}{|l|}{ Generator vs. Inverter } \\
\hline a. Generator & 18.9 & 23.8 & $22 . .0$ \\
\hline Inverter & 81.0 & 76.1 & 78.0 \\
\hline \multicolumn{4}{|c|}{ Type of Petrol Used in Vehicle } \\
\hline a. Unleaded & 79.3 & 76.0 & 77.0 \\
\hline b. Leaded & 20.6 & 23.8 & 23.0 \\
\hline \multicolumn{4}{|c|}{ Preferred Place of Visit for Recreation } \\
\hline a. Religious place & 10.34 & 9.5 & 10.0 \\
\hline Hill station & 56.8 & 66.6 & 61.0 \\
\hline \multicolumn{4}{|l|}{ National park/ } \\
\hline Sanctuary & 13.7 & 11.9 & 13.0 \\
\hline Famous City & 12.07 & 11.9 & 12.0 \\
\hline Both $b$ \& c & 6.8 & 0.0 & 4.0 \\
\hline
\end{tabular}


students were in favor of and 50\% were against this practice. On the question of use of generator vs inverter and unleaded vs. leaded petrol, the environmental consciousness level of students was $78 \%$ and $77 \%$ respectively which is quite high. About $78 \%$ students appreciated natural beauty and therefore they opted for hill station, national park/sanctuary as a place of recreation instead of a famous city or a religious place. Just acquiring the knowledge of environmental issues will not solve the problem. We need to go beyond this, therefore, environmental education should envisage activity-oriented concept as rightly suggested by Yomi Noibi, an African environmental educationist. He stated "learning to be environmentally literate comes through doing something for the environment and not just through learning about the environment" (Guha and Chattopadhyay 2005).

After the survey of 200 university students, scoring was done for each student and it was found that $65 \%$ students fall under moderate category of consciousness, $9 \%$ of them fall in poor category whereas $26 \%$ of the subjects fall in good category of consciousness regarding environmental issues (Table 2). The average scores of consciousness level of under graduate as well as postgraduate students were found to be nearly same i.e., of moderate category.

Policy Implications: To bring about change in behavior of community, people working in the area of environmental education, be it a
Table 2. Environmental consciousness scores of students

\begin{tabular}{llc}
\hline Scores & Category & $\%$ of respondents \\
\hline$<6$ & Poor & 9.0 \\
$6-10$ & Moderate & 65.0 \\
$>10$ & Good & 26.0 \\
\hline
\end{tabular}

government agency or an NGO or voluntary sector at different levels, should join hands to develop an appropriate communication strategy taking into account the use of interpersonal communication and traditional media in addition to electronic and print media to sensitize people on environmental issues.

\section{REFERENCES}

Guha M, Chattopadhyay, A 2005. Environmental education: A pathway for sustainable development, population. ENVIS Centre, 2(4): 7-11.

Kumari V 1998. Environmental Consciousness of Students of Hissar City. M.Sc. dissertation, Guru Jambheshwar University, Hisar.

Mills ES 1978. The Economics of Environmental Quality. Princetone University, New York: W.W. Norton \& Company Inc.

Sabri MA 2004 Environmental Education: some key issues. Kurukshetra, 52(8): 7-11.

Vitterso G 2003 Environmental information and consumption practice - A case study of households in Fridriksad. Professional Report, website-www. sifo.no/page/publication.

WHO SEARO 2004. India Country Health Profile Health and Environment. www.whosea.org 